INL/EXT-15-37524

December 2015

NEAMS-ATF M3 Milestone Report: Literature Review of Modeling of RadiationInduced Swelling in Fe-CrAl Steels

Xianming Bai

S. Bulent Biner

Chao Jiang

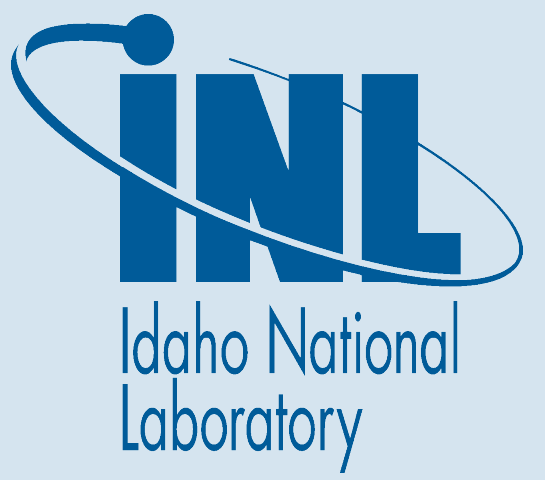




\section{NOTICE}

This information was prepared as an account of work sponsored by an agency of the U.S. Government. Neither the U.S. Government nor any agency thereof, nor any of their employees, makes any warranty, express or implied, or assumes any legal liability or responsibility for any third party's use, or the results of such use, of any information, apparatus, product, or process disclosed herein, or represents that its use by such third party would not infringe privately owned rights. The views expressed herein are not necessarily those of the U.S. Nuclear Regulatory Commission. 


\title{
NEAMS-ATF M3 Milestone Report: Literature Review of Modeling of Radiation-Induced Swelling in Fe-Cr-Al Steels
}

\author{
Xianming Bai \\ S. Bulent Biner \\ Chao Jiang
}

December 2015

\begin{abstract}
Idaho National Laboratory
Fuel Modeling and Simulation Department Idaho Falls, Idaho 83415
\end{abstract}

\author{
Prepared for the \\ U.S. Department of Energy \\ Office of Nuclear Energy \\ Under U.S. Department of Energy-Idaho Operations Office \\ Contract DE-AC07-99ID13727
}




\begin{abstract}
Fe-Cr-Al steels are proposed as accident-tolerant-fuel (ATF) cladding materials in light water reactors due to their excellent oxidation resistance at high temperatures. Currently the understanding of their performance in reactor environment is still limited. In this review, firstly we reviewed the experimental studies of Fe-Cr-Al based alloys with particular focus on the radiation effects in these alloys. Although limited data are available in literature, several previous and recent experimental studies have shown that Fe-Cr-Al based alloys have very good void swelling resistance at low and moderate irradiation doses but the growth of dislocation loops is very active. Overall the behavior of radiation damage evolution is similar to that in $\mathrm{Fe}-\mathrm{Cr}$ ferritic/martensitic alloys. Secondly we reviewed the rate theory based modeling methods for modeling the coevolution of voids and dislocation loops in materials under irradiation such as Frenkel pair three-dimensional diffusion model (FP3DM) and cluster dynamics. Finally, we summarized and discussed our review and proposed our future plans for modeling radiation damage in $\mathrm{Fe}-\mathrm{Cr}-\mathrm{Al}$ based alloys.
\end{abstract}




\section{Table of Contents}

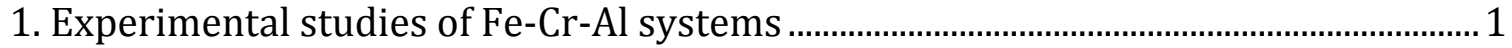

2. Rate theory based modeling of void swelling and dislocation loop growth .............. 3

2.1. Frenkel pair three-dimensional diffusion model (FP3DM) ...................................... 4

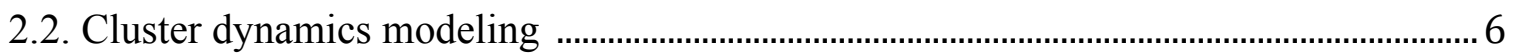

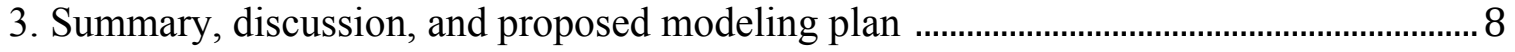

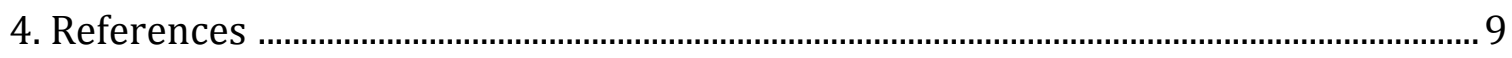




\section{Experimental studies of $\mathrm{Fe}-\mathrm{Cr}-\mathrm{Al}$ systems}

Fe-Cr-Al alloys (also called Fecralloys) are promising accident-tolerant-fuel (ATF) cladding materials in light water reactors $[1,2]$. During oxidation, the Al solute in these alloys can react with oxygen and form an alumina $\left(\mathrm{Al}_{2} \mathrm{O}_{3}\right)$ layer on the alloy surface, acting as a solid-state barrier layer for the inward diffusion of oxygen ions [1]. In comparison with the traditional cladding materials such as zirconium alloys and austenitic stainless steels (304L), Fe-Cr-Al alloys have much better oxidation resistance in high-temperature steam environment in absence of irradiation [1]. For example, recently it has been shown that the oxidation kinetics of some Fe-Cr-Al alloys is about two orders of magnitude slower than that of zirconium alloys at high temperatures [1]. The mechanical properties of a series of Fe-Cr-Al alloys with $10-20 \mathrm{Cr}, 3-5 \mathrm{Al}$, and $0-$ $0.12 \mathrm{Y}$ in weight percent have been tested recently [3]. It has been shown that the tensile properties are insensitive to the alloy composition, although the high-temperature oxidation kinetics strongly depends on both $\mathrm{Cr}$ and $\mathrm{Al}$ contents. Based on these testing results, the $\mathrm{Fe}-13 \mathrm{Cr}-4.5 \mathrm{Al}+\mathrm{Y}$ has been down selected as a base alloy composition for further alloy development [3].

$\mathrm{Fe}-\mathrm{Cr}$-Al alloys are ferritic alloys so that they share some common features as $\mathrm{Fe}-\mathrm{Cr}$ ferritic alloys. For example, Fe-Cr-Al alloys also have a body-center-cubic crystal structure. Due to the the miscibility gap in the $\mathrm{Fe}-\mathrm{Cr}$ alloy system, high-chromium (e.g., $>14 \%$ ) Fe-Cr ferritic/ martensitic alloys can decompose to Fe-rich $(\alpha)$ and Cr-rich $\left(\alpha^{\prime}\right)$ phases and result in embrittlement when the temperature is below $475{ }^{\circ} \mathrm{C}$ [4]. Under irradiation, the precipitation of $\alpha^{\prime}$ phase can occur at even lower $\mathrm{Cr}$ content such as $9 \% \mathrm{Cr}$ due to the radiation enhanced precipitation [5]. As expected, precipitation of $\alpha^{\prime}$ phase also occurs in in Fe-Cr-Al systems [6]. The presence of $\alpha^{\prime}$ phase causes the hardening and embrittlement of these alloys and affects the integrity of the mechanical properties of these alloys.

Unlike the Fe-Cr ferritic/ martensitic alloys for which the radiation-induced microstructural evolution has been studied extensively, very limited studies have been conducted to investigate the microstructural evolution and the change of physical properties in Fe-Cr-Al systems. Little and Stow [7] have investigated the neutronirradiation-induced void swelling in a pure Fe and a number of ferritic steels (including a $\mathrm{Fe}-14 \mathrm{Cr}-4 \mathrm{Al}$ steel) in the temperature range $380-615{ }^{\circ} \mathrm{C}$ to $23 \mathrm{dpa}$ and $30 \mathrm{dpa}$ irradiated in the Dounreay Fast Reactor. The immersion density measurements were used to determine the bulk volumetric swelling. The volume swelling as a function of irradiation temperature for these materials is shown in Fig. 1. Compared with the ferritic steels, the pure $\mathrm{Fe}$ had much larger swelling with a peak swelling of about $0.95 \%$ at $420{ }^{\circ} \mathrm{C}$. In contrast, all the ferritic steels displayed very low swelling, close to or even lower than the detection limit of $0.1 \%$. In the Fe-14Cr-4Al steel, the swelling was only detected at 595

${ }^{\circ} \mathrm{C}$. Further transmission electron microscopy (TEM) analysis also revealed that very few or no voids formed in the Fe-14Cr-4Al steel. The experimental work demonstrates that the solute elements in ferritic steels can suppress the void swelling significantly. It also indicates that in term of swelling behavior the Fe-Cr-Al system behaves similarly as other $\mathrm{Fe}-\mathrm{Cr}$ based ferritic steels. For Fe-Cr binary alloys, it has been shown that the void swelling depends on the $\mathrm{Cr}$ content. The swelling is lowest when the $\mathrm{Cr}$ concentration is about $5 \sim 6 \mathrm{wt} \%$ [7]. 


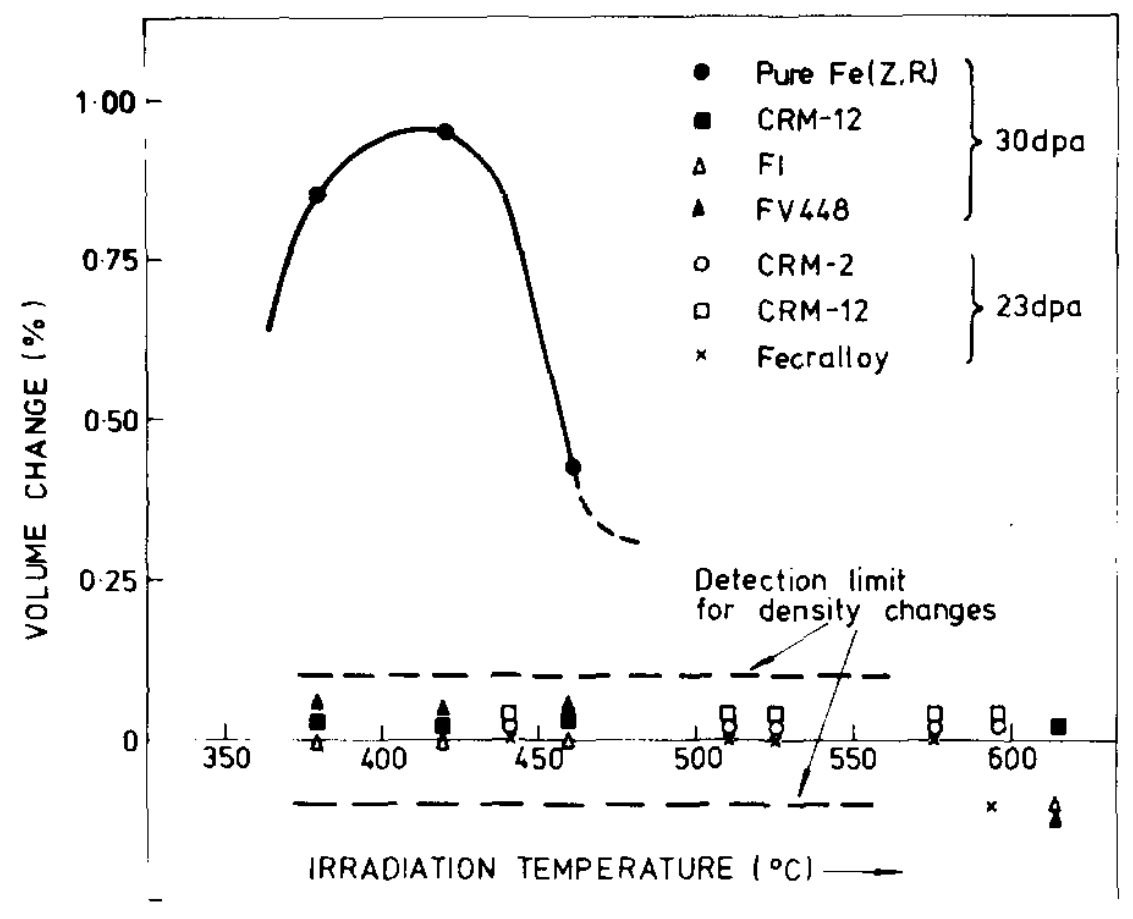

Fig. 1. Void swelling as a function of irradiation temperature for pure $\mathrm{Fe}$ and ferritic/martensitic steels (including a Fe-14Cr-4Al Fecralloy) under neutron irradiation to 23 dpa and 30 dpa [7].

Very recently, Field et al. [6] investigated the neutron-irradiation-induced microstructural evolution in four Fe-Cr-Al alloys with $10-18 \mathrm{Cr}$ and $2.9-4.8 \mathrm{Al}$ in weight percent irradiated in the High Flux Isotope Reactor (HFIR) at $382{ }^{\circ} \mathrm{C}$ to $1.8 \mathrm{dpa}$. Consistent with Little and Stow's work, they also concluded that very few or no cavities were created by irradiation in these alloys. Therefore, these alloys have very good void swelling resistance, at least under the irradiation conditions in their work. However, they observed many dislocation loops in these alloys and the microstructures are shown in Fig. 2. Similar to pure $\mathrm{Fe}$ and $\mathrm{Fe}-\mathrm{Cr}$ alloys $[8,9]$, both $1 / 2<111>$ and $<100>$ loops can form. Although no determination on the loop nature (interstitial-type or vacancy-type) was conducted in this work, it is likely that they are interstitial-type loops as observed in pure $\mathrm{Fe}$ and $\mathrm{Fe}-\mathrm{Cr}$ alloys [9]. In addition to the dislocation loops, black dots and precipitation of $\alpha^{\prime}$ particles were also observed. The number densities and average sizes of dislocation loops and black dots were also estimated using TEM and scanning TEM techniques. These quantities depend on the alloy composition. In general the number densities are in the range of $10^{19}-10^{21} \mathrm{~m}^{-3}$. In $9-18 \mathrm{Cr} \mathrm{Fe}-\mathrm{Cr}$ alloys under neutron irradiation at $563 \mathrm{~K}$ to $1.82 \mathrm{dpa}$, the number density of $\alpha^{\prime}$ particles is in the range of $10^{22}-10^{24} \mathrm{~m}^{-3}$. If we assume the $\mathrm{Fe}-\mathrm{Cr}-\mathrm{Al}$ systems have a similar precipitation behavior as in $\mathrm{Fe}-\mathrm{Cr}$ systems, the number density of $\alpha^{\prime}$ particles can be 2-3 orders of magnitude higher than the density of dislocation loops. Therefore, the mechanical behavior may be dominated by $\alpha^{\prime}$ particles in Fe-Cr-Al systems, particularly in high-Cr alloys [6]. The mean sizes of 
dislocation loops and black dots are in the range of $10-50 \mathrm{~nm}$, which is much larger than the mean size of $1-2 \mathrm{~nm}$ for $\alpha^{\prime}$ particles in Fe-Cr systems [5].
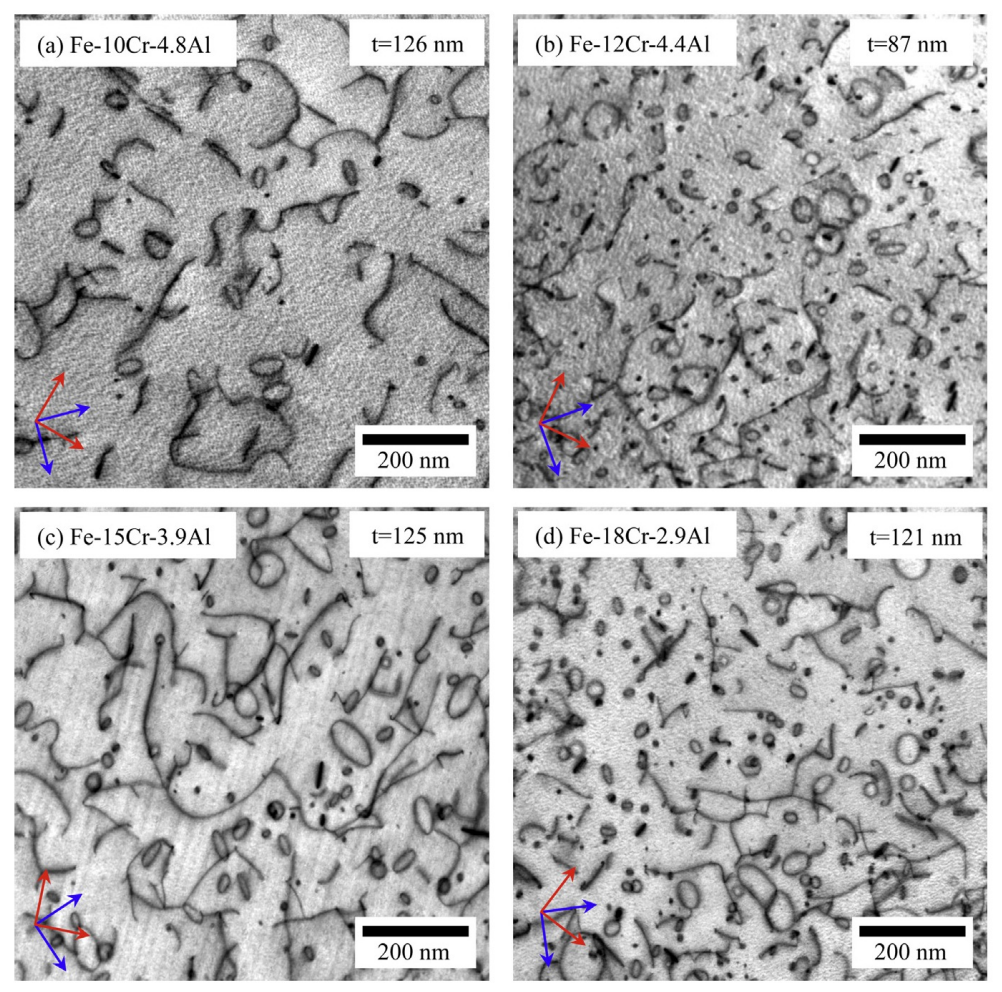

Fig. 2. Dislocation structures in four neutron-irradiated Fe-Cr-Al alloys at $382{ }^{\circ} \mathrm{C}$ to 1.8 dpa [6].

Although the experimental investigations of void swelling in Fe-Cr-Al alloys is still limited, it is clear that these materials have very good void swelling resistance at low and moderate irradiation doses, which is similar to Fe-Cr ferritic/martensitic alloys [10, 11]. However, it is unknown whether Fe-Cr-Al alloys still maintain the low-swelling behavior at high irradiation doses. Typically Fe-based ferritic/martensitic alloys have long incubation doses for swelling but the swelling accelerates at high doses [11, 12]. Therefore, developing mechanistic models to predict the swelling behavior in these materials at a wide range of irradiation doses is important. In addition, the evolution of dislocation loops affects the mechanical properties of these materials significantly. Therefore, modeling the evolution of dislocation loops is also very important. In the following, we review some modeling methods for modeling the coevolution of voids and dislocation loops in materials under irradiation.

\section{Rate theory based modeling of void swelling and dislocation loop growth}

Rate theory based approaches have been widely used to model the evolution of voids and dislocation loops under irradiation [13]. Rate theory is a mean-field approach in which defects, clusters, microstructural features are assumed to distribute homogenously in the system. Typically rate theory models ignore the spatially dependent defect interaction processes so that there is no spatial resolution in the models. However, such a coarse- 
grain approach enables the modeling of the evolution of voids and loops at much longer time and higher doses than many spatially resolved methods can do. There are many derivatives of rate-theory based models [14-18]. Typically they can be classified into two classes: Frenkel pair three-dimensional diffusion model (FP3DM) and cluster dynamics (CD) model.

\subsection{Frenkel pair three-dimensional diffusion model (FP3DM)}

FP3DM is an early rate-theory-based model to describe the evolution of point defects, voids and dislocation loops under irradiation and the review of this model is given in Ref. [13]. In this model, only Frenkel pairs (mono-interstitials and mono-vacancies) are produced so that it is more suitable for modeling the electron irradiation. Point defects can migrate in 3D and interact with defect sinks. Dislocations interact with interstitials more strongly than with vacancies: the so-called dislocation bias which is the driving force for void swelling. For the growth of voids and dislocation loops, only the evolution of their mean sizes is modeled because the model assumes that they have no size distribution. The nucleation process is not considered so that the number densities of voids and loops are input parameters. In addition, the coarsening of voids and loops is also ignored.

Under irradiation, both interstitials and vacancies are produced. If temperature is high, thermal vacancies also can be generated. When defects diffuse to sinks, they can either be annihilated or accumulate to form voids and loops. When interstitials and vacancies meet, they recombine. The rate equations to describe the time-evolution of vacancy concentration $\left(C_{v}\right)$ and interstitial concentration $\left(C_{i}\right)$ are:

$$
\begin{aligned}
& \frac{d C_{v}}{d t}=G^{N R T}+G_{v}^{t h}-k_{v}^{2} D_{v} C_{v}-\mu_{R} D_{i} C_{i} C_{v}, \\
& \frac{d C_{i}}{d t}=G^{N R T}-k_{i}^{2} D_{i} C_{i}-\mu_{R} D_{i} C_{i} C_{v} .
\end{aligned}
$$

In Eq. (1), $t$ is time; $G^{N R T}$ is defect production rate which is a product of dpa rate and cascade efficiency; $G_{v}^{\text {th }}$ is thermal vacancy generation rate which is related to vacancy formation energy; $k_{v}^{2}$ is vacancy sink strength and the expression depends on the sink type; $D_{v}$ and $D_{i}$ are vacancy and interstitial diffusion coefficients, respectively; $\mu_{R}$ is recombination constant between vacancies and interstitials. Similar meanings are for the symbols in Eq. (2). The void growth rate is related the concentration of interstitials and vacancies. The time-evolution of void radius $\left(R_{\text {void }}\right)$ can be described as,

$$
\frac{d R_{v o i d}}{d t}=\frac{1}{R_{\text {void }}}\left[D_{v} C_{v}-D_{i} C_{i}-D_{v} C_{v}^{t h} \exp \left(\frac{2 \Omega \tilde{\gamma}}{R_{\text {void }} k_{B} T}\right)\right],
$$

where $C_{v}^{t h}$ is the thermal vacancy concentration, $\Omega$ is atomic volume, $\tilde{\gamma}$ is surface energy, $k_{B}$ is Boltzmann constant, and $T$ is temperature. For interstitial-type dislocation loops, the time-evolution of the dislocation loop radius $\left(R_{\text {loop }}\right)$ is also related to the defect concentration, 


$$
\frac{d R_{\text {loop }}}{d t}=\frac{1}{b}\left[z^{i} D_{i} C_{i}-z^{v} D_{v} C_{v}+z^{v} D_{v} C_{v}^{t h} \exp \left(-\frac{\left(\gamma_{s l}+E_{e l}\right) b^{2}}{k_{B} T}\right),\right.
$$

where $b$ is Burgers vector; $z^{i}$ and $z^{v}$ are defect capture efficiencies by dislocation loops for interstitials and vacancies, respectively. Typically they are set to the same values as those for line dislocations; $\gamma_{s l}$ is stacking fault energy and $E_{e l}$ is the interaction energy of point defects with dislocations.

Equations (1) - (4) are fully coupled. For example, the evolution of interstitial and vacancy concentrations affect the void and loop growth rates; the changes of void and loop radii also affect their respective sink strengths and thus the defect concentrations. The volumetric swelling $(S)$ due to void swelling can be directly calculated from $R_{\text {void }}$. If temperature is not very high and the thermal vacancy emission can be ignored, the volumetric swelling rate can also be be calculated as,

$$
\left.\frac{d S}{d t}=\frac{d(\Delta V / V)}{d t}=k_{v o i d}^{2}\left[D_{v} C_{v}-D_{i} C_{i}\right)\right]
$$

Figure 3 shows an example of rate theory modeling of the evolution of point defects, void swelling, and vacancy supersaturation as a function of dose (or time) in the FP3DM framework [13]. These properties can be calculated from Eqs. (1) - (5) if the input parameters are given. The authors also showed the evolution of di-vacancies and void density. However, since the authors did not provide details of their calculation, it is unclear how these properties can be calculated from the basic FP3DM model. Probably a modified FP3DM model was used.

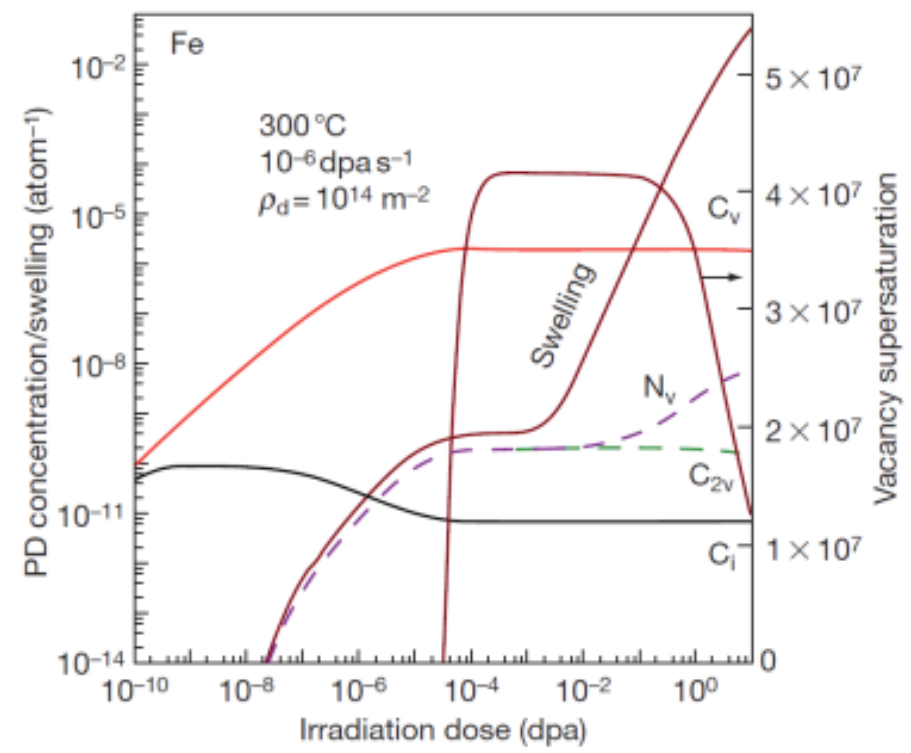

Fig. 3. An example of using FP3DM to model the evolution of point defects, void swelling, vacancy super saturation, and void number density [13]. 
Since the basic FP3DM model does not include the defect clustering effects, the model is more suitable for radiation damage evolution under electron irradiation in which only Frenkel pairs are produced. To investigate cascade effects, the production bias model (PBM) has been developed [15], which is an extension of the FP3DM model. It has been shown that this model can model void swelling under different irradiation particles. However, PBM may only model radiation damage at low doses $(<1 \mathrm{dpa})$ and in pure metals [13].

\subsection{Cluster dynamics modeling}

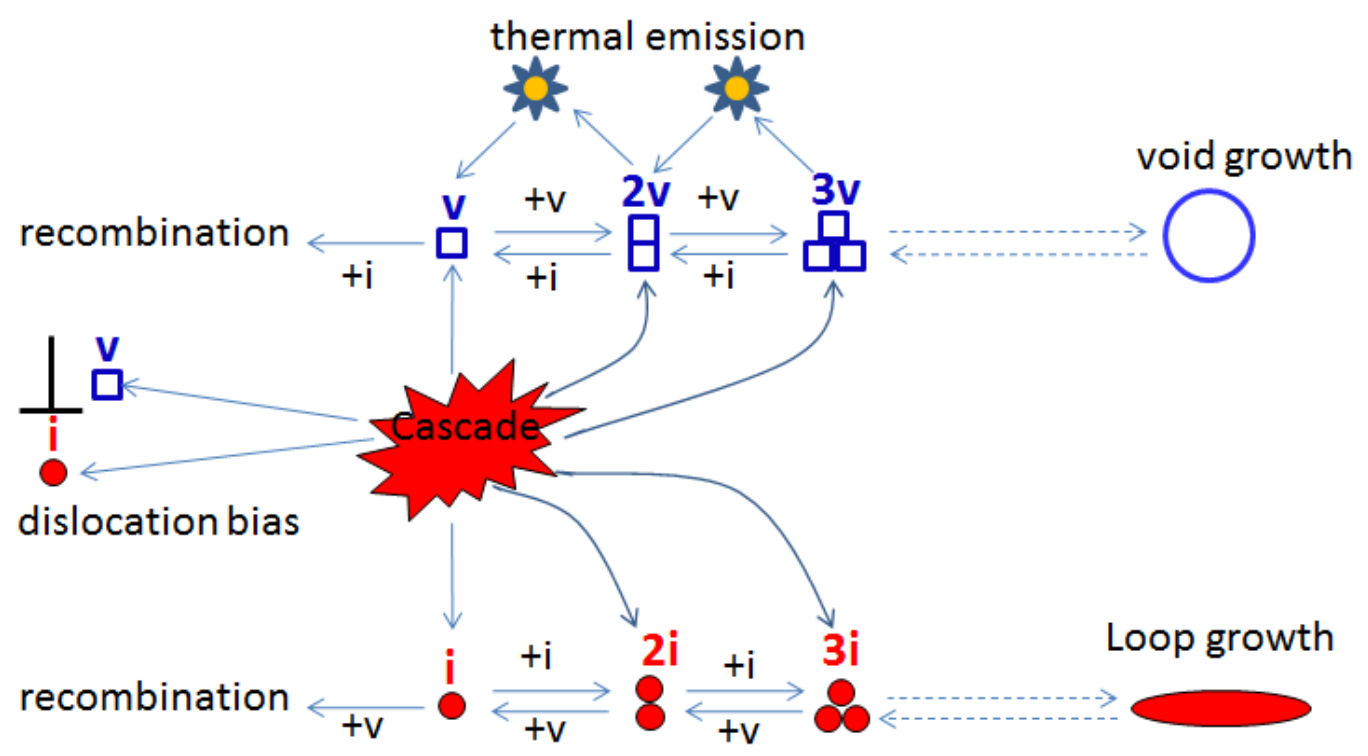

Fig. 4. Schematic illustration of cluster dynamics modeling of the evolution of voids and dislocation loops under irradiation.

As mentioned earlier, in the conventional FP3DM model voids and dislocation loops do not have a size distribution and only the mean radii are calculated. In addition, the nucleation and coarsening of these microstructural features are not modeled either. Moreover, the defect clustering effects are also neglected. These assumptions limit the applicability of the FP3DM model for modeling the microstructural evolution in realistic conditions. An alternative to FP3DM is cluster dynamics (CD) method [17]. A schematic illustration of this method is shown in Fig. 4. Cascades can produce not only Frenkel pairs, but also some small clusters. These clusters can directly contribute to the nucleation of defect clusters through a heterogeneous nucleation process (in addition to the homogenous nucleation through the diffusive encounter of defects). For the simplest case, only point defects are assumed to be mobile, although this assumption can be released in the CD framework [18]. Similar to the FP3DM model, point defects can be annihilated by defect sinks such as line dislocations, grain boundaries, etc. Again dislocations have a dislocation bias. When a point defect meets a defect or a cluster of the same type, they accumulate and the cluster grows. On the other hand, when a point defect meets a defect or a cluster of opposite type, recombination occurs. These processes will 
lead to growth or shrinkage of voids and dislocation loops. In addition, vacancy clusters or voids also can thermally emit vacancies which will result in the coarsening of voids. For interstitial loops, the thermal emission of interstitials is typically neglected [17] but the process can be conveniently included in the modeling if necessary. The voids are typically assumed to have a spherical geometry. The interstitial clusters or dislocation loops can be treated either as a sphere or a disk.

A good description of the basic cluster dynamics model can be found in Ref. [17]. In cluster dynamics, every type of point defects and defect clusters has a concentration. Here $f(x)$ represents the size distribution function of clusters or the cluster concentration for cluster size of $x$, where $\mathrm{x}$ represents the number of defects in the cluster. For concentration of point defects (mono-interstitials and mono-vacancies), the conventional symbol $C$ is still used to differentiate the concentration of clusters. The master equations for vacancy clusters $(v c l)$ and interstitial clusters $(i c l)$ are:

$$
\begin{aligned}
& \frac{d f_{v c l}(x)}{d t}=K_{v c l}(x)+J_{v c l}(x-1)-J_{v c l}(x), \\
& \frac{d f_{i c l}(x)}{d t}=K_{i c l}(x)+J_{i c l}(x-1)-J_{i c l}(x) .
\end{aligned}
$$

In Eq. (6), $K_{v c l}(x)$ and $J_{v c l}(x)$ represent the cluster production rate in cascades and flux of the vacancy cluster with size of $x$, respectively. Similar meanings are for interstitial clusters in Eq. (7). The fluxes of vacancy clusters and interstitial clusters have the following expressions:

$$
\begin{aligned}
& J_{v c l}(x)=P_{v c l}(x) f_{v c l}(x)-Q_{v c l}(x+1) f_{v c l}(x+1), \\
& J_{i c l}(x)=P_{i c l}(x) f_{i c l}(x)-Q_{i c l}(x+1) f_{i c l}(x+1) .
\end{aligned}
$$

The vacancy absorption rate by a $3 \mathrm{D}$ void of size $x$ is

$$
P_{v c l}(x)=\left(\frac{48 \pi^{2}}{\Omega^{2}}\right)^{1 / 3} x^{1 / 3} D_{v} C_{v} .
$$

The vacancy release rate from a void is the sum of the absorption rate of interstitials and the emission rate of vacancies:

$$
Q_{v c l}(x)=\left(\frac{48 \pi^{2}}{\Omega^{2}}\right)^{1 / 3} x^{1 / 3}\left[D_{i} C_{i}+D_{v} \exp \left(-\frac{E_{v}^{b}(x)}{k_{B} T}\right)\right],
$$

where $E_{v}^{b}(x)$ is vacancy binding energy with a vacancy cluster and is size dependent. The absorption and release rates for interstitial clusters are similar to Eq. (10) and (11), but the interstitial emission term may be ignored as mentioned before. If interstitial clusters are 2D, the geometry factors (the first term at the right-hand side in Eqs. (10) and (11)) also need be changed [17].

For mobile defects such as interstitials and vacancies, the rate equations are similar to Eqs. (1) and (2), but in a more complex form as shown in Ref. [17]. Solving the point defect rate equations together with Eqs. (6) - (11), the time evolution of point defects and 
all type of defect clusters can be obtained. The volumetric swelling is related to the number of vacancies accumulated in vacancy clusters as

$$
S=\frac{\Delta V}{V}=\sum_{n \geq 2} x f_{v c l}(x) .
$$

Figure 5 shows an example of using cluster dynamics to model the radiation damage evolution in pure Fe. At a given irradiation dose, cluster dynamics can provide the size distributions of defect clusters. The number density of vacancies accumulated in vacancy clusters as a function of irradiation dose also can be obtained. If this quantity is multiplied by the atomic volume, it can be converted to void swelling.
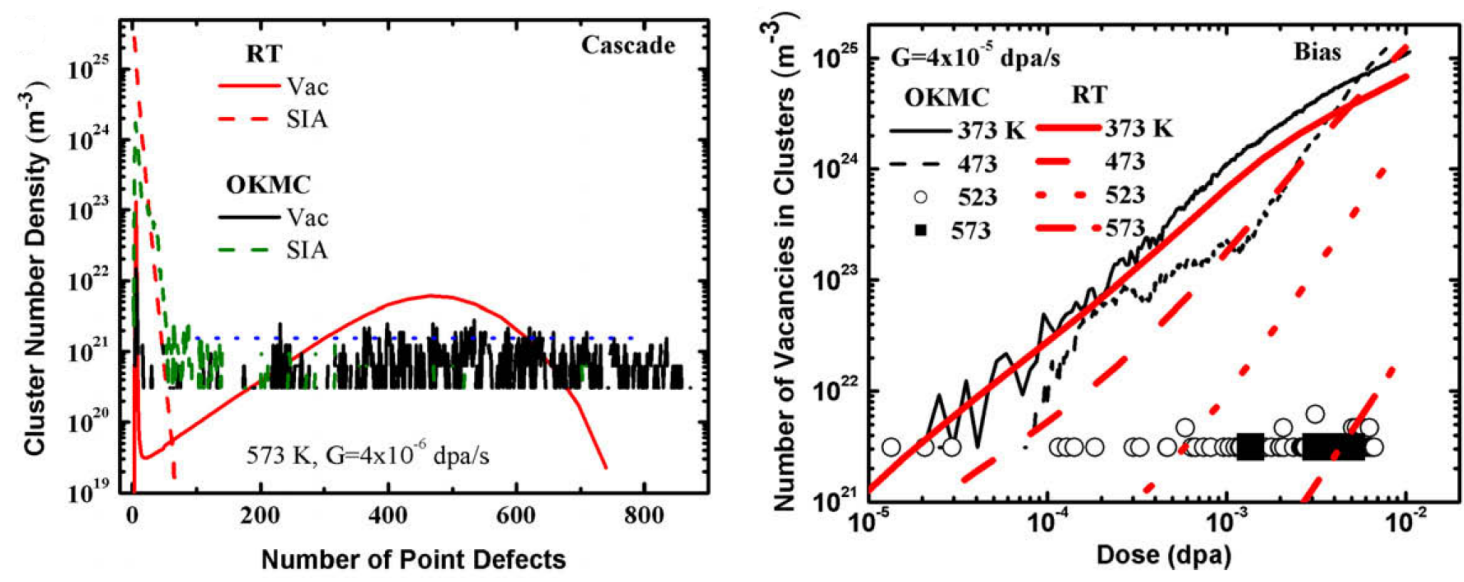

Fig. 5. Cluster dynamics modeling of radiation damage evolution in pure Fe [17]. (Left) Interstitial and vacancy cluster size distribution (i.e., cluster densities as a function of cluster size). (Right) Number density of vacancies in vacancy clusters as a function of irradiation dose.

\section{Summary, discussion, and proposed modeling plan}

In this review, we reviewed some experimental work of the void swelling and microstructural evolution in Fe-Cr-Al alloys under irradiation, the rate theory based models such as FP3DM and cluster dynamics for modeling void swelling and dislocation loop evolution. In our future work, we plan to use these rate-theory based models to model the void swelling and dislocation loop evolution in $\mathrm{Fe}-\mathrm{Cr}-\mathrm{Al}$ systems under irradiation. Previously, the rate theory based models have been widely used to model radiation damage and void swelling behavior in a wide range of materials. In many cases, however, only pure metals are modeled for simplicity. Sometimes these models were used to model radiation damage in alloy systems [19] although interstitials and vacancies were not treated as species-dependent. Nevertheless, these simplifications make it possible to use the rate theory based models to model radiation damage evolution. In our future work, at least as an initial step, such a simplification will also be adopted. However, the alloy-specific materials properties such as defect diffusion coefficients should be used to distinguish alloys from pure metals. 
As Fig. 1 shows the void swelling in Fe-based ferritic steels (including the Fe-Cr-Al steel) has a much lower swelling than pure Fe. This experimental work indicates that the effects of alloy elements on damage evolution must be properly captured in our modeling. Little [20] proposed a few mechanisms to interpret why ferritic steels have a better void swelling resistance than a pure Fe: (1) The solute atoms in ferritic steels can trap point defects and thus enhance point defect recombination. The trapping is likely between vacancies and interstitial carbon atoms and between vacancies and solute lattice atoms; (2) The solute-dislocation interaction suppresses the dislocation bias, and thus the preferential absorption of interstitials is weaker than in pure Fe; (3) Solute atoms inhibit the dislocation climb. In the future some atomistic modeling may be conducted to investigate these hypotheses and provide justifications or input parameters for rate theory based modeling.

Since the radiation damage evolution behavior in $\mathrm{Fe}-\mathrm{Cr}-\mathrm{Al}$ alloys behave similarly as in $\mathrm{Fe}-\mathrm{Cr}$ ferritic alloys, we also plan to model the damage evolution in $\mathrm{Fe}-\mathrm{Cr}$ systems as a starting point. The $\mathrm{Cr}$-composition-dependent defect diffusivities in $\mathrm{Fe}-\mathrm{Cr}$ alloys were calculated previously [21] and these results may be used for our modeling to capture the alloy composition effects. Many experimental data of $\mathrm{Fe}-\mathrm{Cr}$ systems are also available in literature so that we can use them to calibrate our models. In the future, the effect of $\mathrm{Al}$ on the defect diffusion in Fe-Cr-Al alloys will be investigated using atomistic modeling (such as density functional theory). The obtained defect energetics and kinetics from atomistic modeling may be provided to kinetic Monte Carlo simulations to obtain the effective defect diffusion coefficients in the presence of $\mathrm{Al}$.

Currently direct modeling of the coevolution of lattice defect features (e.g., voids and loops) and precipitates (such as $\alpha^{\prime}$ particles) are still very limited. However, the density of $\alpha^{\prime}$ particles is very high in Fe-Cr based ferritic steels so that they may provide additional sinks for mobile defects. To include this effect, we may assume $\alpha^{\prime}$ particles as fix-density sinks in our modeling. Their density may be obtained from experiments [5].

\section{References}

[1] B. A. Pint, K. A. Terrani, M. P. Brady, T. Cheng, and J. R. Keiser, High temperature oxidation of fuel cladding candidate materials in steam-hydrogen environments, Journal of Nuclear Materials 440, 420-427 (2013).

[2] K. A. Terrani, S. J. Zinkle, and L. L. Snead, Advanced oxidation-resistant ironbased alloys for LWR fuel cladding, Journal of Nuclear Materials 448, 420-435 (2014).

[3] Y. Yamamoto, B. A. Pint, K. A. Terrani, K. G. Field, Y. Yang, and L. L. Snead, Development and property evaluation of nuclear grade wrought $\mathrm{FeCrAl}$ fuel cladding for light water reactors, Journal of Nuclear Materials 467, Part 2, 703716 (2015).

[4] P. J. Grobner, The $885^{\circ} f\left(475^{\circ}\right.$ c) embrittlement of ferritic stainless steels, Metallurgical Transactions 4, 251-260 (1973).

[5] M. Bachhav, G. Robert Odette, and E. A. Marquis, $\alpha^{\prime}$ precipitation in neutronirradiated $\mathrm{Fe}-\mathrm{Cr}$ alloys, Scripta Materialia 74, 48-51 (2014). 
[6] K. G. Field, X. Hu, K. C. Littrell, Y. Yamamoto, and L. L. Snead, Radiation tolerance of neutron-irradiated model $\mathrm{Fe}-\mathrm{Cr}-\mathrm{Al}$ alloys, Journal of Nuclear Materials 465, 746-755 (2015).

[7] E. A. Little, and D. A. Stow, Void-swelling in irons and ferritic steels, Journal of Nuclear Materials 87, 25-39 (1979).

[8] Z. Yao, M. Hernández-Mayoral, M. L. Jenkins, and M. A. Kirk, Heavy-ion irradiations of $\mathrm{Fe}$ and $\mathrm{Fe}-\mathrm{Cr}$ model alloys Part 1: Damage evolution in thin-foils at lower doses, Philosophical Magazine 88, 2851-2880 (2008).

[9] Z. Yao, M. L. Jenkins, M. Hernández-Mayoral, and M. A. Kirk, The temperature dependence of heavy-ion damage in iron: A microstructural transition at elevated temperatures, Philosophical Magazine 90, 4623-4634 (2010).

[10] D. S. Gelles, Void swelling in binary FeCr alloys at 200 dpa, Journal of Nuclear Materials 225, 163-174 (1995).

[11] B. H. Sencer, and F. A. Garner, Compositional and temperature dependence of void swelling in model $\mathrm{Fe}-\mathrm{Cr}$ base alloys irradiated in the EBR-II fast reactor, Journal of Nuclear Materials 283-287, Part 1, 164-168 (2000).

[12] F. A. Garner, M. B. Toloczko, and B. H. Sencer, Comparison of swelling and irradiation creep behavior of fcc-austenitic and bcc-ferritic/martensitic alloys at high neutron exposure, Journal of Nuclear Materials 276, 123-142 (2000).

[13] S. I. Golubov, A. V. Barashev, and R. E. Stoller, Radiation Damage Theory, in Comprehensive Nuclear Materials, edited by R. J. M. Konings (Elsevier, Oxford, 2012), pp. 357-391.

[14] D. Xu, B. D. Wirth, M. Li, and M. A. Kirk, Combining in situ transmission electron microscopy irradiation experiments with cluster dynamics modeling to study nanoscale defect agglomeration in structural metals, Acta Materialia 60, 4286-4302 (2012).

[15] B. N. Singh, and A. J. E. Foreman, Production bias and void swelling in the transient regime under cascade damage conditions, Philosophical Magazine A 66, 975-990 (1992).

[16] J. Marian, and V. V. Bulatov, Stochastic cluster dynamics method for simulations of multispecies irradiation damage accumulation, Journal of Nuclear Materials 415, 84-95 (2011).

[17] R. E. Stoller, S. I. Golubov, C. Domain, and C. S. Becquart, Mean field rate theory and object kinetic Monte Carlo: A comparison of kinetic models, Journal of Nuclear Materials 382, 77-90 (2008).

[18] A. Hardouin Duparc, C. Moingeon, N. Smetniansky-de-Grande, and A. Barbu, Microstructure modelling of ferritic alloys under high flux $1 \mathrm{MeV}$ electron irradiations, Journal of Nuclear Materials 302, 143-155 (2002).

[19] A. Gokhman, A. Ulbricht, U. Birkenheue, and F. Bergner, Cluster Dynamics Study of Neutron Irradiation Induced Defects in Fe-12.5at\% Cr Alloy, Solid State Phenomena 172-174, 449-457 (2011). 
[20] E. A. Little, Void-swelling in irons and ferritic steels: I. Mechanisms of swelling suppression, Journal of Nuclear Materials 87, 11-24 (1979).

[21] D. Terentyev, N. Castin, and C. J. Ortiz, Correlated recombination and annealing of point defects in dilute and concentrated $\mathrm{Fe}-\mathrm{Cr}$ alloys, Journal of Physics: Condensed Matter 24, 475404 (2012). 